\title{
Mid-arm circumference is a reliable method to estimate adiposity in preterm and term infants
}

\author{
Kelly M. Daly-Wolfe ${ }^{1,2}$, Kristine C. Jordann ${ }^{1,2}$, Hillarie Slater ${ }^{1}$, Joanna C. Beachy ${ }^{1}$ and Laurie J. Moyer-Mileur ${ }^{1}$
}

BACKGROUND: Premature birth is associated with increased adipose deposition after birth. Standard anthropometry (body weight, length, and head circumference) may not adequately assess fat deposition. Validated methods to assess adiposity are needed to optimize growth quality in preterm infants. The purpose of this study was to identify covariates of infant body fat. METHODS: Air displacement plethysmography (ADP), standard anthropometry, and body circumferences were measured at hospital discharge in preterm $(n=28 ; 31-35$ wk postmenstrual age (PMA)) and term ( $n=28 ; 38-41$ wks PMA) infants.

RESULTS: Body weight, length, and head circumference were lower for preterm infants $(P<0.05)$ at hospital discharge compared with that of term infants. Despite smaller body size and younger PMA, preterm infant percent body fat (\%BF) by ADP was $12.33 \pm 4.15 \%$ vs. $9.64 \pm 4.01 \%$ in term infants $(P=0.01)$. Mid-arm circumference (MAC) is a covariate of $\% B F$ in both preterm and term infants (adjusted $R^{2}=0.49 ; P<0.001$ ). In preterm infants alone, MAC accounted for $60.4 \%$ of the variability of percent body fat (\%BF) by ADP $(P<0.01)$.

CONCLUSIONS: Preterm infants have increased body fat deposition as they approach term-corrected age, and MAC is a reliable, low-cost measure for monitoring infant body fat deposition in preterm and term infants.

$\mathbf{P}$ remature deliveries account for $12 \%$ of the live births in the United States $(1,2)$. The American Academy of Pediatrics recommends catch-up growth, defined as weight and length gain greater than the intrauterine growth rate for the gestational age, in the first weeks of life for preterm infants $(3,4)$. However, adequately nourishing and promoting proper growth in preterm infants is challenging, and inadequate postnatal growth is often observed in the neonatal intensive care unit. Some studies suggest that the catch-up growth is necessary for preterm infant brain development but may have deleterious consequences for metabolic and cardiovascular health (3). The American Academy of Pediatrics also recommends that a preterm infant's body composition mimic intrauterine body composition until term age (5). However, current research demonstrate that preterm infants at term-corrected age have higher total body and/or abdominal fat compared with term infants, suggesting that adequate catch-up growth is not achieved postnatally (5-8). Precise determination of body composition in premature infants may aid health professionals in selecting appropriate interventions to ensure proper postnatal growth and development.

It is unclear whether the increased preterm infant adiposity is due to an adaptation to the extrauterine environment and/or a combination of other causes (9). Theories regarding increased body fat in preterm compared with term infants include fat deposition related to illness, excessive calories administered by the health care team to ensure catch-up growth, maintenance of fluid balance and thermoregulation, or other stress after birth (9-11). For example, premature infants have increased circulating levels of cortisol compared with term cohorts $(10,11)$. Furthermore, cortisol is commonly associated with stress and has been shown to promote total body/abdominal fat deposition $(10,11)$. Overall, increased infant fat deposition is undesirable and is associated with an increased risk of metabolic syndrome, obesity, and diabetes mellitus in later life (12).

Infant body composition measurements provide insight on growth patterns, diet adequacy, and efficacy of medical interventions (5). Air displacement plethysmography (ADP) is a method for body adiposity measurement that was recently validated in infants (13). ADP instruments are portable, do not use radiation, are very precise, and have the potential to be a safe and convenient replacement for traditional body composition methods such as magnetic resonance imaging and dual-energy x-ray absorptiometry. However, ADP may not be available in many health care settings, and continuous measurements may be costly to patients. Additional low-risk, body composition methodologies include standard anthropometry (weight, length, and head circumference), body circumferences, and skinfold thicknesses. Studies that evaluate and compare these body composition measurement techniques to assess postnatal growth are needed.

The aims of this study are: (i) to confirm differences in fat distribution in preterm and term infants; (ii) to identify covariates that relate to preterm and term infant body fat; (iii) to determine differences in salivary cortisol between preterm and term infants; and (iv) to document the influence of caloric and protein intake on body composition of preterm infants. 
We hypothesized that: (i) body fat deposition will be greater in prematurely born infants compared with infants born at term; (ii) percent body fat by ADP will correlate positively with midarm and mid-thigh circumference; tricep, bicep, subscapular, and suprailiac skinfold thickness, and derived anthropometry (BMI, ponderal index); (iii) salivary cortisol will be greater in preterm infants at birth and hospital discharge compared with term infants; and (iv) preterm infant caloric and protein intake will not be correlated with body fat percentage.

\section{RESULTS}

There were no statistically significant differences between familial characteristics of preterm and term cohorts (Table 1). Maternal age, prepregnancy BMI, and total pregnancy weight gain varied widely in both cohorts. Less than half of the preterm and term mothers (preterm: $35.0 \%, n=10$; term: $35.0 \%$, $n=10$ ) were classified as overweight or obese (prepregnancy BMI $\geq 25 \mathrm{~kg} / \mathrm{m}^{2}$ ). The majority of the mothers for both preterm and term infants reported taking prenatal vitamins during their pregnancy $(82.1 \% ; n=46)$. Furthermore, mothers of both cohorts reported similar levels of physical activity before and during pregnancy. The levels of maternal education were high school $(30.4 \% ; n=17)$, some college/technical school (17.9\%; $n=10)$, bachelor's degree (19.6\%; $n=11)$, associate's degree $(16.1 \% ; n=9)$, postgraduate degree $(10.7 \% ; n=6)$, and unfinished high school or other $(5.4 \% ; n=3)$. Overall, $14.3 \%$ $(n=4)$ of the preterm mothers and $7.1 \%(n=2)$ of the term mothers smoked and/or consumed alcohol during pregnancy. Mothers had a variety of medical conditions, with gestational diabetes being the most common $(10.7 \% ; n=3)$. The average paternal age was $30.77 \mathrm{y}(\mathrm{SD}=7.70 \mathrm{y})$ for preterm infants and 32.79 y $(S D=6.33$ y) for term infants. Paternal obesity for preterm and term infants was $42.9 \%(n=12)$ and $65.4 \%(n=17)$, respectively.

During the study period, 28 preterm infants and 28 term infants were enrolled. The demographic information for preterm and term cohorts at baseline and hospital discharge is summarized in Table 2. Males represented slightly less than

Table 1. Maternal characteristics of preterm and term infants

\begin{tabular}{lcc}
\hline & $\begin{array}{c}\text { Preterm infants } \\
(n=28)\end{array}$ & $\begin{array}{c}\text { Term infants } \\
(n=28)\end{array}$ \\
\hline $\begin{array}{l}\text { Gravida (number of } \\
\text { pregnancies) }\end{array}$ & $2.79 \pm 1.71$ & $3.32 \pm 3.06$ \\
$\begin{array}{lcc}\text { Para (number of living children) } \\
\text { Maternal age (years) }\end{array}$ & $2.39 \pm 1.66$ & $2.39 \pm 2.06$ \\
$\begin{array}{l}\text { Prepregnancy BMI }\left(\mathrm{kg} / \mathrm{m}^{2}\right) \\
\text { Total pregnancy weight gain }(\mathrm{kg})\end{array}$ & $29.00 \pm 6.64$ & $29.96 \pm 5.81$ \\
$\begin{array}{l}\text { Mothers who took prenatal } \\
\text { vitamins }\end{array}$ & $23.56 \pm 6.01$ & $24.14 \pm 5.05$ \\
$\begin{array}{l}\text { Physical activity before } \\
\text { pregnancy (days/week) }\end{array}$ & $2.20 \pm 2.26$ & $12.31 \pm 4.86$ \\
$\begin{array}{l}\text { Physical activity during } \\
\text { pregnancy (days/week) }\end{array}$ & $1.54 \pm 2.08$ & $23(82.1 \%)$ \\
\hline
\end{tabular}

All values are means \pm SDs unless otherwise noted. half the sample population in both preterm and term infant cohorts. Birth gestation was $33.34 \mathrm{wk}(\mathrm{SD}=0.94 \mathrm{wk})$ for preterm infants and $39.35 \mathrm{wk}(\mathrm{SD}=0.84 \mathrm{wk})$ for term infants. Additionally, the majority of total infants were of non-Hispanic, Caucasian descent $(75.0 \% ; n=42)$. All preterm infants and $96.4 \%(n=27)$ term infants were born appropriate for gestational age. The most common indications for maternal preterm labor were unspecified $(60.7 \% ; n=17)$, pregnancyinduced hypertension/preeclampsia $(28.6 \% ; n=8)$, placenta acreta $(7.1 \% ; n=2)$, and infection $(3.6 \% ; n=1)$. The average Apgar score was $7(\mathrm{SD}=2)$ at $1 \mathrm{~min}$ and $8(\mathrm{SD}=1)$ at $5 \mathrm{~min}$ for preterm infants, and the number of weekly measurements ranged from two to six, averaging $3.64(\mathrm{SD}=1.34)$.

At discharge, preterm infant body weight, length, and body circumferences were significantly lower than term infants $(P<0.05)$ using corrected gestational age as a covariate. Also, preterm infant BMI and ponderal index were significantly lower than term infants after adjusting for gestational age (Table 2). Subscapular and suprailiac skinfolds were significantly larger in preterm infants compared with term infants

Table 2. Characteristics of preterm and term infants at baseline and hospital discharge

\begin{tabular}{|c|c|c|}
\hline & $\begin{array}{l}\text { Preterm infants } \\
\qquad(n=28)\end{array}$ & $\begin{array}{l}\text { Term infants } \\
(n=28)\end{array}$ \\
\hline Number of male subjects & $13(46.4 \%)$ & $12(42.9 \%)$ \\
\hline Gestation at birth (PMA weeks) & $33.34 \pm 0.94^{*}$ & $39.35 \pm 0.84$ \\
\hline Number of non-Hispanic white & $19(67.9 \%)$ & $23(82.1 \%)$ \\
\hline Number of Hispanic & $9(32.1 \%)$ & $5(17.9 \%)$ \\
\hline \multicolumn{3}{|l|}{ First measurement } \\
\hline Gestational age (PMA weeks) & $33.89 \pm 0.95$ & - \\
\hline Weight (g) & $1,883.3 \pm 330.6$ & - \\
\hline Length $(\mathrm{cm})$ & $43.61 \pm 2.10$ & - \\
\hline Head circumference $(\mathrm{cm})$ & $30.36 \pm 1.37$ & - \\
\hline Mid-arm circumference (cm) & $7.89 \pm 0.80$ & - \\
\hline Mid-thigh circumference $(\mathrm{cm})$ & $10.94 \pm 1.22$ & - \\
\hline Abdominal circumference $(\mathrm{cm})$ & $24.91 \pm 2.08$ & - \\
\hline $\mathrm{BMI}\left(\mathrm{kg} / \mathrm{m}^{2}\right)$ & $9.91 \pm 1.06$ & - \\
\hline Ponderal index $\left(\mathrm{kg} / \mathrm{m}^{3}\right)$ & $22.71 \pm 2.12$ & - \\
\hline \multicolumn{3}{|l|}{ Hospital discharge } \\
\hline Gestational age (PMA weeks) & $36.28 \pm 1.28^{*}$ & $39.55 \pm 0.84$ \\
\hline Weight (g) & $2,419.5 \pm 397.3^{*}$ & $3,098.1 \pm 373.8$ \\
\hline Length $(\mathrm{cm})$ & $45.71 \pm 1.98^{*}$ & $49.27 \pm 1.91$ \\
\hline Head circumference (cm) & $32.44 \pm 1.50^{*}$ & $34.29 \pm 1.17$ \\
\hline Mid-arm circumference (cm) & $8.90 \pm 0.77^{*}$ & $11.05 \pm 1.18$ \\
\hline Mid-thigh circumference (cm) & $12.95 \pm 1.28^{*}$ & $14.74 \pm 1.67$ \\
\hline Abdominal circumference $(\mathrm{cm})$ & $28.30 \pm 2.45^{*}$ & $30.77 \pm 2.37$ \\
\hline $\mathrm{BMI}\left(\mathrm{kg} / \mathrm{m}^{2}\right)$ & $11.56 \pm 1.05^{*}$ & $12.72 \pm 0.91$ \\
\hline Ponderal index $\left(\mathrm{kg} / \mathrm{m}^{3}\right)$ & $25.28 \pm 1.88^{*}$ & $25.83 \pm 1.79$ \\
\hline
\end{tabular}


Table 3. Skinfold measurement at discharge in preterm and term infants

\begin{tabular}{lcc}
\hline & Preterm infants & Term infants \\
\hline Tricep skinfold $(\mathrm{mm})$ & $3.44 \pm 0.82(n=11)$ & $3.25 \pm 0.59(n=28)$ \\
Bicep skinfold $(\mathrm{mm})$ & $3.06 \pm 0.68(n=10)$ & $2.65 \pm 0.61(n=26)$ \\
Subscapular skinfold $(\mathrm{mm})$ & $3.93 \pm 0.89^{* *}(n=11)$ & $3.38 \pm 0.61(n=28)$ \\
Suprailiac skinfold $(\mathrm{mm})$ & $2.89 \pm 0.88^{*}(n=9)$ & $2.41 \pm 0.60(n=25)$
\end{tabular}

All values are means \pm SDs unless otherwise noted.

ANCOVA, analysis of covariance.

${ }^{*} P \leq 0.01 ;{ }^{* *} P<0.05$, significantly different from term infants, ANCOVA.

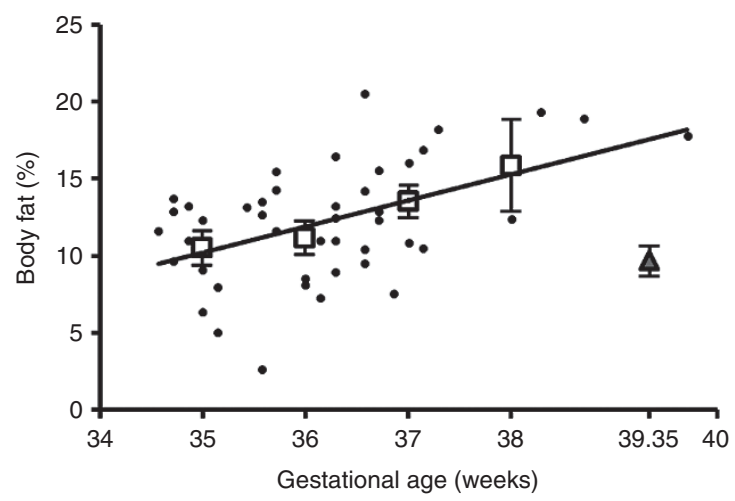

Figure 1. Percent body fat by air displacement plethysmography of preterm infants at time points above $34.5 \mathrm{wk}$ corrected gestational age compared with percent body fat of term infants. Black circles indicate preterm infants; white squares indicate average preterm infants; and gray triangle indicates average term infants. Error bars represent SE. $R^{2}=0.2514$ for trendline. Average \%BF was $10.50 \%$ at $35 \mathrm{wk}(n=12), 11.15 \%$ at $36 \mathrm{wk}$ $(n=15), 13.50 \%$ at $37 \mathrm{wk}(n=15)$, and $15.87 \%$ at $38 \mathrm{wk}(n=2)$.

Table 4. Correlation between body fat measurement by air displacement plethysmography, anthropometrics, and skinfolds

\begin{tabular}{lrr}
\hline & $\begin{array}{c}\text { Preterm } \\
\text { infants (\%BF) }\end{array}$ & \multicolumn{1}{c}{$\begin{array}{c}\text { Term infants } \\
(\% \mathrm{BF})\end{array}$} \\
\hline Mid-arm circumference $(\mathrm{cm})$ & $0.47^{* *}(n=28)$ & $0.67^{*}(n=28)$ \\
Mid-thigh circumference $(\mathrm{cm})$ & $0.53^{*}(n=28)$ & $0.61^{*}(n=28)$ \\
Abdominal circumference $(\mathrm{cm})$ & $0.33(n=28)$ & $0.54^{*}(n=28)$ \\
Tricep skinfold $(\mathrm{mm})$ & $0.42(n=11)$ & $0.40^{* *}(n=28)$ \\
Bicep skinfold $(\mathrm{mm})$ & $0.46(n=10)$ & $0.02(n=26)$ \\
Subscapular skinfold $(\mathrm{mm})$ & $0.59(n=11)$ & $0.54^{*}(n=28)$ \\
Suprailiac skinfold $(\mathrm{mm})$ & $0.75^{* *}(n=10)$ & $0.57^{*}(n=25)$ \\
\hline
\end{tabular}

Results are listed as Spearman correlation coefficients.

${ }^{*} P \leq 0.01 ; * * 0.05$.

when correcting for gestational age. Tricep and bicep skinfolds were not significantly different between cohorts (Table 3 ).

The average baseline cortisol level for preterm infants was $0.40 \mu \mathrm{g} / \mathrm{dl}(\mathrm{SD}=0.38 \mu \mathrm{g} / \mathrm{dl} ; n=26)$, and the average discharge cortisol level was $0.33 \mu \mathrm{g} / \mathrm{dl}(\mathrm{SD}=0.52 \mu \mathrm{g} / \mathrm{dl} ; n=20)$, which was not significantly different. The average cortisol level for term infants $(0.21 \pm 0.23 \mu \mathrm{g} / \mathrm{dl})$ was significantly lower than that of preterm infants at baseline $(P<0.05$; ANOVA) but did not differ from preterm infant levels at discharge.

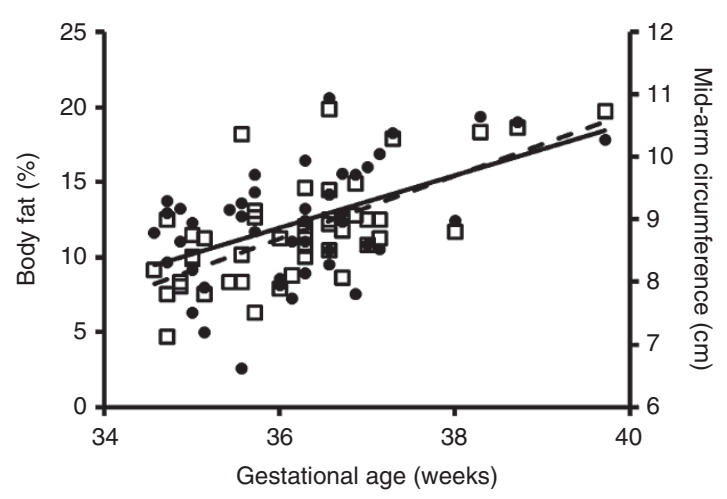

Figure 2. Comparison of percent body fat by air displacement plethysmography and mid-arm circumference in preterm infants from birth to hospital discharge. Black circles indicate body fat (\%); white squares indicate mid-arm circumference $(\mathrm{cm})$; black trendline indicate body fat trendline; and dashed trendline indicate mid-arm circumference trendline. $R^{2}=0.2514$ for body fat trendline and $R^{2}=0.4292$ for mid-arm circumference trendline.

The average percent body fat of infants tested with the ADP system was $12.33 \%(\mathrm{SD}=4.15 \%)$ for preterm infants and $9.64 \%$ $(\mathrm{SD}=4.01 \%)$ for term infants at discharge and was statistically different upon gestational age correction $(P=0.01$; analysis of covariance (ANCOVA); Figure 1).

Table 4 shows the results of the Spearman correlation analysis of preterm and term infants, with the significant positive correlations indicated. In preterm infants, correlation coefficients of mid-arm circumference (MAC), mid-thigh circumference, and suprailiac skinfold were statistically significant. In term infants, significant correlations were obtained except between bicep skinfold thickness and percent body fat. Also, calculated BMI correlated positively with percent body fat in preterm infants $(r=0.44 ; P<0.05)$ and in term infants $(r=0.71 ; P<0.001)$. Lastly, ponderal index correlated with percent body fat in preterm and term infants $(r=0.41$ preterm; $r=0.51$ term $P<0.05)$.

ADP and anthropometric measurements were compared with a stepwise linear regression in preterm and term infants. MAC and suprailiac skinfold were covariates of percent body fat in both preterm and term infants (adjusted $R^{2}=0.49$ vs. 0.41 ; $P<0.001)$. In preterm infants alone, the MAC accounted for $60.4 \%$ of the variability of percent body fat by ADP $(P=0.008)$. Figure 2 shows the comparison between percent body fat by $\mathrm{ADP}$ and MAC in preterm infants. On the contrary, BMI accounted for $56.1 \%$ of the variability and mid-thigh circumference accounted for $63.0 \%$ of the variability of percent body fat by $\operatorname{ADP}(P<0.001)$ in term infants.

Gender differences were not observed at baseline or discharge in gestational age, body weight, length, body circumferences, skinfolds, and percent body fat by ADP in preterm or term infants. Interestingly, data stratification based on gender revealed strong correlations among term infants (Table 5). For instance, mid-arm and abdominal circumferences strongly correlated to \%BF in term male infants, and suprailiac skinfold strongly correlated to \% BF in female term infants. However, significant, gender-based correlations were not observed in preterm infants. 
Table 5. Correlation between body fat by air displacement plethysmography, anthropometrics, and skinfolds in male and female infants

\begin{tabular}{|c|c|c|c|c|}
\hline & \multicolumn{2}{|c|}{$\begin{array}{l}\text { Preterm infants } \\
\text { (\%BF) }\end{array}$} & \multicolumn{2}{|c|}{$\begin{array}{c}\text { Term infants } \\
\text { (\%BF) }\end{array}$} \\
\hline & Male & Female & Male & Female \\
\hline Mid-arm circumference $(\mathrm{cm})$ & $\begin{array}{c}0.57^{*} \\
(n=13)\end{array}$ & $\begin{array}{c}0.29 \\
(n=15)\end{array}$ & $\begin{array}{c}0.80^{*} \\
(n=12)\end{array}$ & $\begin{array}{c}0.60^{*} \\
(n=16)\end{array}$ \\
\hline Mid-thigh circumference $(\mathrm{cm})$ & $\begin{array}{c}0.65^{*} \\
(n=13)\end{array}$ & $\begin{array}{c}0.42 \\
(n=15)\end{array}$ & $\begin{array}{c}0.44 \\
(n=12)\end{array}$ & $\begin{array}{c}0.66^{*} \\
(n=16)\end{array}$ \\
\hline Abdominal circumference $(\mathrm{cm})$ & $\begin{array}{c}0.13 \\
(n=12)\end{array}$ & $\begin{array}{c}0.37 \\
(n=15)\end{array}$ & $\begin{array}{l}0.80^{*} \\
(n=12)\end{array}$ & $\begin{array}{c}0.50^{*} \\
(n=16)\end{array}$ \\
\hline Tricep skinfold (mm) & $\begin{array}{c}0.32 \\
(n=6)\end{array}$ & $\begin{array}{c}0.53 \\
(n=5)\end{array}$ & $\begin{array}{c}0.39 \\
(n=12)\end{array}$ & $\begin{array}{c}0.41 \\
(n=16)\end{array}$ \\
\hline Bicep skinfold (mm) & $\begin{array}{c}0.43 \\
(n=6)\end{array}$ & $\begin{array}{c}0.80 \\
(n=4)\end{array}$ & $\begin{array}{c}0.67^{*} \\
(n=11)\end{array}$ & $\begin{array}{l}-0.28 \\
(n=15)\end{array}$ \\
\hline Subscapular skinfold (mm) & $\begin{array}{c}0.49 \\
(n=6)\end{array}$ & $\begin{array}{c}0.70 \\
(n=5)\end{array}$ & $\begin{array}{c}0.55 \\
(n=12)\end{array}$ & $\begin{array}{c}0.56^{*} \\
(n=16)\end{array}$ \\
\hline Suprailiac skinfold (mm) & $\begin{array}{c}0.71 \\
(n=6)\end{array}$ & $\begin{array}{c}0.95 \\
(n=4)\end{array}$ & $\begin{array}{c}0.57 \\
(n=10)\end{array}$ & $\begin{array}{c}0.70^{*} \\
(n=15)\end{array}$ \\
\hline
\end{tabular}

Results are listed as Spearman correlation coefficients.

${ }^{*} P<0.05$.

Within the first week of life, $92.9 \%(n=26)$ of preterm infants received a combination of parenteral and enteral nutrition, while $42.9 \%(n=12)$ of preterm infants exclusively received breast milk or fortified breast milk at discharge. Of the term infants, $92.9 \%(n=26)$ were exclusively breastfed. During the hospital stay, $46.4 \%(n=13)$ of preterm infants received a multivitamin and $10.7 \%(n=3)$ received at least one bolus of caffeine. At baseline, the average caloric intake for preterm infants was $91.48 \mathrm{kcal} / \mathrm{kg} / \mathrm{d}(\mathrm{SD}=16.59 \mathrm{kcal} / \mathrm{kg} / \mathrm{d})$ and the average protein intake was $3.07 \mathrm{~g} / \mathrm{kg} / \mathrm{d}(\mathrm{SD}=0.58 \mathrm{~g} / \mathrm{kg} / \mathrm{d})$. The mean daily caloric and protein intake per body weight over the week before discharge was $111.78 \mathrm{kcal} / \mathrm{kg} / \mathrm{d}(\mathrm{SD}=12.80 \mathrm{kcal} / \mathrm{kg} / \mathrm{d})$ and $3.25 \mathrm{~g} / \mathrm{kg} / \mathrm{d}(\mathrm{SD}=0.52 \mathrm{~g} / \mathrm{kg} / \mathrm{d})$, respectively, for preterm infants. Using Spearman's correlations, significant correlations were not observed between average calories or protein per body weight per day and body fat percentage from the ADP system.

\section{DISCUSSION}

Our study provides support for previous research indicating that preterm infants near or at term-corrected age have a higher percent body fat than infants born term (5-8). Furthermore, our findings indicate that anthropometry, skinfolds, and ADP are efficient to detect significant differences in body composition between preterm and term infants at hospital discharge. Interestingly, the increased body fat of preterm infants suggests that current recommendations are not effective to achieve normalized body composition postnatally.

We demonstrated that preterm infant body fat percentage is higher than term infants upon gestational age correction. This result suggests that the effect of prematurity on preterm infant body composition may be occurring as early as the first week of life. Overall, preterm infant body fat percentage demonstrates an upward trend as age approaches term corrected age (Figure 1).

Skinfold measurement was added to the study protocol midway through data collection resulting in a smaller sample size. Nevertheless, these data show that subscapular and suprailiac skinfold measurements were larger in preterm than the term infant group at hospital discharge. This result suggests that subcutaneous fat deposition is occurring in preterm infants. Interestingly, tricep and bicep skinfold measurements did not vary between cohorts implying that subcutaneous fat deposition occurs centrally. While fat deposition may also occur viscerally, the methodology of this study was not geared to differentiate between subcutaneous and visceral body fat.

Importantly, we identified reliable methods of body composition measurement that correlate with body fat percentage in preterm and term infants when the ADP system is not available. Our findings indicate that MAC and suprailiac skinfold are significant covariates of percent body fat in both preterm and term infants. Percent body fat by ADP and MAC trend upward in a similar manner in preterm infants (Figure 2). As hypothesized, ADP correlated strongly with suprailiac skinfold and moderately with mid-arm and mid-thigh circumference in preterm infants. Unexpectedly, abdominal circumference and tricep, bicep, and subscapular skinfolds did not statistically correlate with body fat percentage. Thus, while body weight is recommended as a growth assessment tool in preterm infants, coordination with a variety of body composition methodologies may provide a better analysis of growth quality.

Our results indicate that gender, stress, and calorie/protein intake may not play a significant role in body fat deposition. Current research correlating gender differences to infant body composition is unclear. This study suggests that covariates of body fat may be gender specific in term infants, but not preterm infants, as evidenced by the strong correlations reported in term infant males and females. Salivary cortisol varied between preterm and term infants only at baseline, suggesting that within the first days of life, preterm infants are under more stress than term infants. However, salivary cortisol levels did not correlate with body fat percentage. To note, the study was not able to control for factors that affect salivary cortisol levels such as sleep cycle or recent exposure to care-giver activities or clinical procedures (14). Lastly, the lack of correlation between preterm infant caloric intake and body fat is consistent with other research studies $(5,15)$. However, unlike this study, other studies have shown a relationship between protein intake and lean mass $(6,16)$. Overall, the current study results on gender, salivary cortisol levels, and dietary intake need to be interpreted with caution due to the small sample size.

In conclusion, this study provides a foundation to test interventions designed to modulate fat deposition and improve growth quality of preterm infants. We demonstrate that infant body composition differs between preterm and term infants and that MAC and suprailiac skinfold for both preterm and term infants are accurate, low-risk, methods to assess infant body composition when ADP techniques are not available. 
Further research is needed to understand additional variables that affect body fat deposition and localization.

\section{METHODS}

This research was a comparative study in which premature infant body composition at term-corrected age and full-term infant body composition at discharge were examined. The University of Utah Institutional Review Board for Human Subjects approved the study protocol.

\section{Subjects}

Premature infants admitted to the University of Utah Hospital neonatal intensive care unit and term infants from the University of Utah Hospital Well Baby Nursery were recruited, and informed parental consent was obtained. Premature infants were born between 31 0/7 and $351 / 7 \mathrm{wk}$ gestation at birth and term infants were born between 37 6/7 to 41 1/7 wk gestation at birth. Eligible infants had birth weight, length, and head circumference between the 1st and 90th percentiles (National Center for Health Statistics growth curve) for gestational age (17). Exclusion criteria included chromosomal abnormalities, major congenital anomalies, major surgery, severe central nervous system injury (asphyxia, congenital hydrocephalus), inborn errors of metabolism, assisted ventilation, inability to start enteral feedings by $96 \mathrm{~h}$ of age, and conditions known to interfere with delivery of enteral feedings or postnatal growth.

Preterm infant physical measurements were completed within 72$96 \mathrm{~h}$ of birth and weekly thereafter until hospital discharge or term gestation ( $38 \mathrm{wk}$ postmenstrual age). Full-term infants were measured within 24-72 h of birth.

\section{Maternal History Questionnaire}

The maternal history questionnaire assessed factors known to be associated with the outcome of a pregnancy. The questionnaire included the following items: race, education level, prepregnancy weight, predelivery weight; paternal age, weight, height; and past pregnancies. Additional items addressed current medical conditions and medications taken during pregnancy. Lastly, the amount of physical activity prior to and during pregnancy was inquired.

\section{Measurements}

Body weight was measured with infants during a quiet state using a digital electronic bed scale (COSMED, Rome, Italy). Length was evaluated using a standard infant length board (Seca, Birmingham, UK). Head, mid-arm, mid-thigh, and abdominal circumferences were assessed using a vinyl-coated fiberglass tape. Tricep, bicep, subscapular, and suprailiac skinfold thicknesses were measured using Lange (Beta Technology, Santa Cruz, CA) skinfold calipers. Mid-arm and mid-thigh circumferences and skinfolds were taken on the left side of the body. Measurements were done in triplicate until values fell within $0.3 \mathrm{~cm}$ of one another, and the reported value is represented as the average of the three measurements.

Saliva was collected before each measurement session onto filter paper as previously described (18). Saliva samples were stored at room temperature and analyzed using ELISA technology (Diagnostic Systems Laboratory, Dexter, TX). Samples were processed in duplicate, and the reported cortisol value is represented as the mean.

Body composition by ADP was obtained with a PEA POD (COSMED). ADP utilizes the inverse relationship between volume and pressure in two enclosed chambers to determine whole body density. A two-compartment model then uses whole-body density to calculate fat and fat-free mass percentages. Measurements were completed in duplicate with a third measurement taken only if the body fat percentages were not within $2 \%$. The final value is represented as the average of the measurements.

The 24-h intake and medication information was retrieved from the PowerChart (Cerner, Kansas City, MO) medical records and recorded from birth to the last day on study. Dietary intake data included source (IV and/or enteral), type (dextrose solution, human milk, or commercial formula), and fluid volume. Calories and protein for breast milk were estimated using $20 \mathrm{kcal} / \mathrm{oz}$ and $8 \%$ of total calories for protein and adjusted based on fortification (19). Medication use was tracked to identify exposure to medications that may impact postnatal growth (caffeine and vitamin/mineral supplements).

\section{Statistical Analysis}

The hypothesis that body fat deposition will be greater in prematurely born infants compared with infants born at term was tested by oneway ANOVA. ANCOVA was used to detect differences in means with the covariate as corrected gestational age. If the assumption of homogeneity of regression was not achieved, $t$-tests were used to confirm results of ANCOVA. The hypothesis that \%BF by ADP will correlate positively with derived anthropometry (BMI, ponderal index) was tested by Spearman correlation with a $r$ value of $0.50-0.69$ defined as a moderate correlation and a $r$ value of $0.70-1.00$ defined as a high correlation (20). Potential confounders and effect measure modifiers for those associations were evaluated and added to the analyses by multivariate analyses of variance and/or multiple linear regression modeling. Statistical analyses were performed using SPSS (version 20; SPSS, Chicago, IL), and significance was set as $P<0.05$.

\section{ACKNOWLEDGMENT}

The authors thank Kimberly Neff and Karen Wheeler for their assistance with infant measurements and data entry.

\section{STATEMENT OF FINANCIAL SUPPORT}

This study was supported by the Division of Neonatology, Department of Pediatrics, University of Utah; the Center for Clinical and Translational Science, University of Utah; and the Pediatric Nutrition Practice Group.

\section{Disclosure: No financial conflicts of interest to disclose.}

\section{REFERENCES}

1. Wang ML, Dorer DJ, Fleming MP, Catlin EA. Clinical outcomes of nearterm infants. Pediatrics 2004;114:372-6.

2. Centers for Disease Control and Prevention. National Prematurity Awareness Month, What is Premature Birth? 2014. (http://www.cdc.gov/features/ prematurebirth/.)

3. Sauer PJ. Can extrauterine growth approximate intrauterine growth? Should it? Am J Clin Nutr 2007;85:608S-13S.

4. McLeod G, Sherriff J. Preventing postnatal growth failure-the significance of feeding when the preterm infant is clinically stable. Early Hum Dev 2007;83:659-65.

5. Roggero P, Giannì ML, Amato O, et al. Is term newborn body composition being achieved postnatally in preterm infants? Early Hum Dev 2009;85:349-52.

6. Roggero P, Giannì ML, Amato O, et al. Influence of protein and energy intakes on body composition of formula-fed preterm infants after term. J Pediatr Gastroenterol Nutr 2008;47:375-8.

7. Uthaya S, Thomas EL, Hamilton G, Doré CJ, Bell J, Modi N. Altered adiposity after extremely preterm birth. Pediatr Res 2005;57:211-5.

8. Cooke RJ, Rawlings DJ, McCormick K, et al. Body composition of preterm infants during infancy. Arch Dis Child Fetal Neonatal Ed 1999;80:F18891.

9. Giannì ML, Roggero P, Liotto N, et al. Postnatal catch-up fat after late preterm birth. Pediatr Res 2012;72:637-40.

10. Levitt NS, Lambert EV, Woods D, Hales CN, Andrew R, Seckl JR. Impaired glucose tolerance and elevated blood pressure in low birth weight, nonobese, young south african adults: early programming of cortisol axis. J Clin Endocrinol Metab 2000;85:4611-8.

11. Kapoor A, Dunn E, Kostaki A, Andrews MH, Matthews SG. Fetal programming of hypothalamo-pituitary-adrenal function: prenatal stress and glucocorticoids. J Physiol 2006;572(Pt 1):31-44.

12. Hales $\mathrm{CN}$, Ozanne SE. For debate: fetal and early postnatal growth restriction lead to diabetes, the metabolic syndrome and renal failure. Diabetologia 2003;46:1013-9.

13. Ramel SE, Gray HL, Davern BA, Demerath EW. Body composition at birth in preterm infants between 30 and 36 weeks gestation. Pediatr Obes 2015;10:45-51.

14. Antonini SR, Jorge SM, Moreira AC. The emergence of salivary cortisol circadian rhythm and its relationship to sleep activity in preterm infants. Clin Endocrinol (Oxf) 2000;52:423-6. 
15. Giannì ML, Roggero P, Taroni F, Liotto N, Piemontese P, Mosca F. Adiposity in small for gestational age preterm infants assessed at term equivalent age. Arch Dis Child Fetal Neonatal Ed 2009;94:F368-72.

16. Koo WW, Hockman EM. Posthospital discharge feeding for preterm infants: effects of standard compared with enriched milk formula on growth, bone mass, and body composition. Am J Clin Nutr 2006;84:1357-64.

17. Centers for Disease Control and Prevention. Growth Charts, 2010. (http:// www.cdc.gov/growthcharts/.)
18. Neu M, Goldstein $M$, Gao D, Laudenslager ML. Salivary cortisol in preterm infants: validation of a simple method for collecting saliva for cortisol determination. Early Hum Dev 2007;83: 47-54.

19. Hazinski MF. Nursing Care of the Critically Ill Child. 3rd edn. St Louis, MO: CV Mosby, 2013:235.

20. Munro BH. Statistical Methods for Health Care Research. 5th edn. Philadelphia, PA: Lippincott Williams \& Wilkins, 2004:512. 